\title{
Opportunities and Risks of the Agile Software Development Management in the IT Field. Case study: IT Companies between 2009-2018
}

\author{
Maria Alexandra MAASSEN ${ }^{11}$
}

\begin{abstract}
The IT sector has been one of the most active and dynamic fields, stimulating innovation and research for multiple fields in the last fifty years. As customer needs and competition requirements are changing, the software development models of the IT companies have also evolved, especially in the direction from a static (Waterfall) to an dynamic perspective (Agile), by involving customers and stakeholders directly into the production process. The main objective of the paper is to analyze specific characteristics of the Agile model implemented in IT companies between 2009-2018. As a methodology the Delphi method based on interviews and questionnaires was used in order to obtain an overview of the subject from IT specialists using the Agile model. The results indicated a clear orientation towards the Agile model as a main method of the software development in the IT sector.
\end{abstract}

Keywords: Agile, software development, IT, management, innovation

JEL classification: M12, M14, E50

DOI 10.24818/RMCI.2018.3.234

\section{Introduction}

For the past fifty years the IT industry has been one of the main active industries in the world, contributing with research and development of products and services in all fields of activity. As financial results over 4,5 trillion \$ in 2017 were obtained in the IT sector, the United States dominating the technology market globally with a percentage of $31 \% 2018$ (Comptia, 2018). As the life cycles of the IT products are decreasing, innovations and new products are introduced to the market to satisfy new customer needs, thus, making innovation and restructuring traditional versions of software development necessary.

The dynamic pace of innovation and integrating customer requirements brought the frequent use of the Agile model within IT companies, that allows frequent improved product releases and direct customer involvement comparing to the traditional model of Waterfall (Ambler, 2004). This use of Agile has been expanded as Waterfall allows in the traditional form a sequence of phases for software development and feedback from stakeholder after the production process has been finalized.

1 Maria Alexandra Maassen, The Bucharest University of Economic Studies, maria_nichifor@ hotmail.com

$234 \quad$ Review of International Comparative Management Volume 19, Issue 3, July 2018 
While the Agile model is considered in the scientific literature to be bringing numerous benefits to the IT companies using it, as well as to adapted innovations to market demands, it is considered it also offers several challenges, especially within the organisation, that needs to restructure the teams, time planning in the context of short time spans for releases and other (Puri, 2009; Canty, 2015).

The objective of the present paper is to analyse the specific characteristics of the Agile model, perceived benefits and weaknesses of the implementation of this model in the case of companies in the IT sector according to experts in the IT field. In order to ensure a practical approach we also interviewed 19 experts in the IT field, that were employed for international players of the IT field. The study reveals the dominance of the Agile model in the case of the participating companies and its effects on the team organisation and product improvements.

Two hypothesis of the study were also formulated:

H1. The Agile model is mostly used by the selected companies in the IT field in comparison to the Waterfall model.

$\mathrm{H} 2$. The Agile model is perceived to have a better orientation towards clients and involves them directly in the software development, increasing the chance for better improvements of the products.

\section{Literature Review}

As mentioned previously, the main two models used in the IT field are Waterfall and Agile. In the present study we will only refer to the Agile model. The Agile model is mostly implemented in the cases of projects, where the competition and requirements change in a dynamic pace and new improvements of the product need to be integrated and released quickly. As nowadays the IT sector is becoming more dynamic and aggressive it is becoming a frequently implemented method of software development.

As represented in Figure 1 the Agile method has the following phases, the feedback from the customer after partially incremented software being the specific characteristic in order to integrate clients' requirements and improvement suggestions in the following version of the product:

The Agile software development model can be classified into two versions, respectively: the Scrum method and the Test driven development.

The Test Driven Development is a version of the Agile method, characterized by the fact that it offers a new approach as test is written before the actual start of software development through coding, thus, it starts with establishing the requirements for the new product feature, as shown by Figure 2 (Parsons et al., 2011). Furthermore, the first test will not pass as the feature is not installed yet and it will pass at the next attempts as the features will be implemented. If all tests pass it means the features were successfully installed. This method is considered to reduce the amount of errors through the frequent testing. 


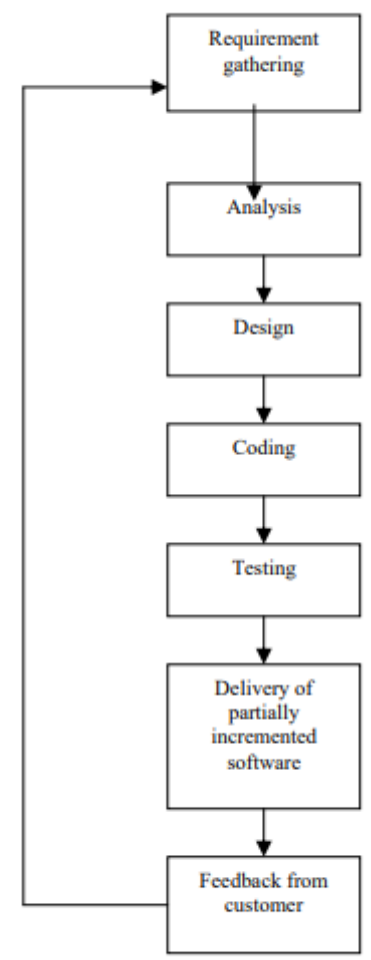

Figure 1. Phases of the Agile model

Source: Sharma et al., 2012

Conjecture

Confirmation
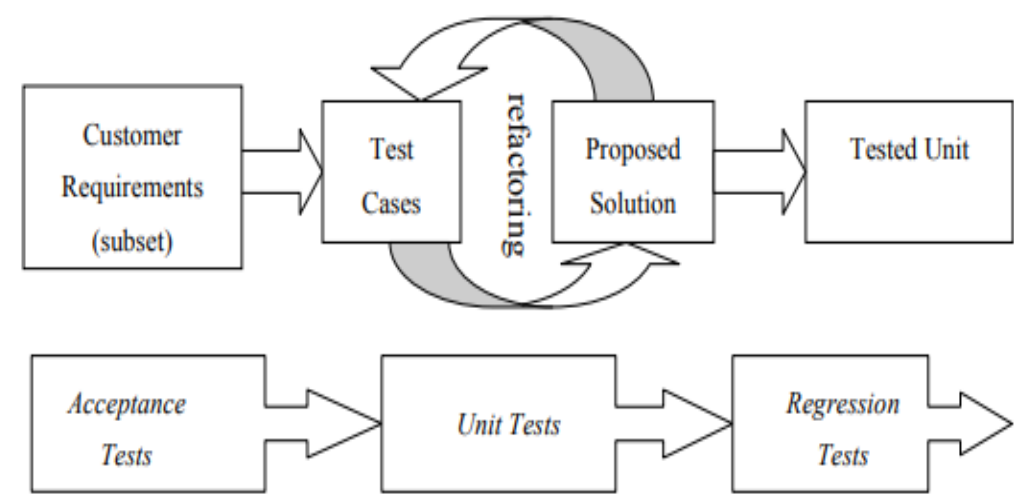

Figure 2. Test driven development model

Source: Parsons et al., 2011 
The Scrum method is another version of the Agile model, that contributes to rapid product releases. The first step is the creation of a list with clients' requirements priorities or a so called product backlog, that served as the basis for the split into objectives for short periods of time, named sprints, that last from three to four weeks (Maximini, 2018). The party establishing the sprints is the project manager. This type of version of the Agile model also requires a dynamic pace of cooperation between the members of the development teams, who have to have daily meetings to discuss software development results and issues in order to find solutions to implement the requirements. As each sprint is finalized a new software release should take place (Chandrasekara, 2017).

The mentioned versions of the Agile model offer multiple benefits, namely: structuring the management and team cooperation more efficiently within companies, as well as the product creation and improvement, elements necessary to adaptation to market characteristics, more competitors from other IT companies and thus, changing customer requirements and needs for permanent innovations in the sector.

The present study offers also an overview from within companies in the IT sector, applying the Agile model, as the scientific literature only emphasizes theoretical aspects of this model, advantages and disadvantages.

Pycek (2009) emphasizes as advantages of the Agile models, as in the case of Agile early identification of errors, decreasing project risk of failure, encouraging other parties communication with teams. Thus, the authors mostly refer to theoretical characteristics of these models and not to practical examples from within the companies.

Other authors also refer to the Agile model with its versions, advantages and risks, but only theoretically (Ashisdeep et al., 2016; Chandra, 2015; Chandrasekara, 2017; Krishna et al., 2012; Maximini, 2018; McHugh et al., 2013; Pope-Ruark, 2015).

Therefore, the present paper brings an overview of the situation of specific characteristics, perceived benefits and risks of Agile model implementation within the IT field from an employees' perspective. The practical inquiry presents perceptions of employees from IT companies, that are international players in the field and offers a basis for further potential research of the practical implementation of the Agile model.

\section{Methodology}

As a method, the Delphi method based on interviews and questionnaires was used to question specialists in the IT field from 19 international IT companies, among which some of the most important IT market players globally. Because 6 of them referred to the Waterfall model as being implemented in their companies, in the present study the other 13 answers will be revealed, that referred to the Agile method. The Delphi method followed the theoretical phases and ensured also a controlled feedback (Buch, 2012). The process followed the phases of: inquiring 
scientific literature on the subject, establishing and definition of the research objective, preparation of questionnaires and interviews, interviews with the participants, results analysis, informing the participants on the results, second round of interviews with the selected specialists, results analysis and the elaboration of the final report, of which the participants were also informed.

All experts, who participated in the present study were IT specialists working for major global players of the IT sector, including: Oracle, Avira Soft S.R.L., Gameloft, Ubisoft, Luxoft, Ixia. The rest of the participating companies names could not be mentioned due to confidentiality reasons. For the practical inquiry two rounds of interviews and questionnaires were established, whereas the first part of the interviews referred to the used software development models in the own company (Waterfall or Agile) and characteristics and advantages of the Agile model, where as the second part referred to obstacles in the Agile implementation and the intention of changing this model in the future in the case of the companies, where the specialists where working at.

As period of employment the 19 selected experts had been working in their company: one to three years (53\%), more than three years up to four years (16\%), more than five years (26\%), less than a year (5\%). The field of activity within the IT sector in the case of the experts using the Agile model included more sectors: software for telecom testing, software for network and telephone devices, online payment platforms, software for browsers, video games, analytics tools, software for CRM, software for payment systems, anti-spam software. All participating experts were employed between 2009-2018 in the IT field.

The 13 respondents, which will considered for this study, were employed in organisations located in Romania, America, Switzerland and England. The experts interviewed were employees of 12 companies, all being international IT companies.

The companies were divided according to the size in terms of number of employees: two companies classified in the dimension of 138000-383000 employees, four companies had 13000 to 85000 employees, five companies had 500-6000 employees and one company had between 11 - 50 employees.

The time span of the practical research spanned between 10th November 2017 and the 10th February 2018.

\section{Empirical results and discussion}

First the selected specialists were divided according to the use of the Agile and Waterfall model, respectively $68 \%$ of the experts implemented Agile in their company, while the rest mentioned the Waterfall model, as illustrated in Figure 3. Only one specialist mentioned both Waterfall and Agile are as models used to develop software products within their departments. 


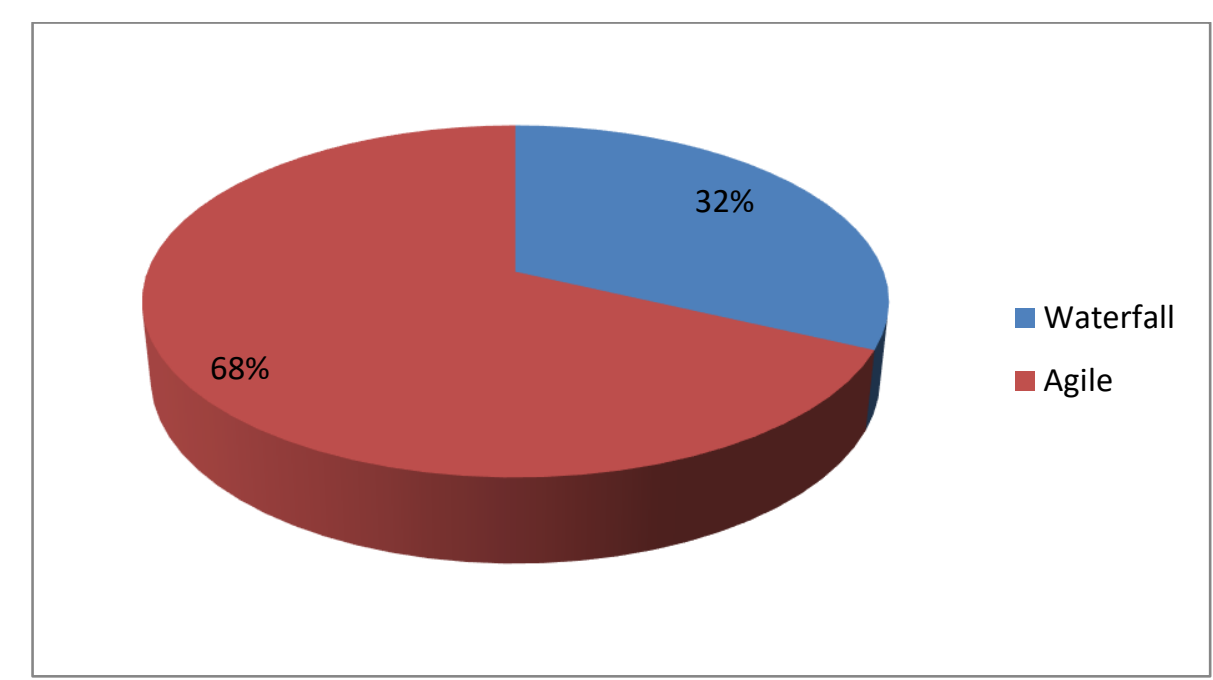

Figure 3. Waterfall vs. Agile software development models in the case of the selected experts

Source: Author's own research

The first inquired aspect about the Agile model referred to the perceived advantages of using this model for software development in the department (socially, financially and from the perspective of communication and integration) from the point of view of the experts using Agile within their department. The most frequently perceived benefit of using Agile was the orientation towards clients through their direct involvement in the software development process, through frequent feedback of releases, that allowed an efficient monitoring of improvements of the products and their improvement through customers' suggestions directly as shown in Figure 4. Secondly, $15 \%$ of the experts mentioned a shorter time to market as a perceived benefit of using this method, while the rest of the advantages, namely better products, better team cooperation were mentioned each by $7 \%$ of the experts. $7 \%$ of the experts mentioned no advantage of using Agile and that it is not beneficial for teamwork, as it adds stress. 


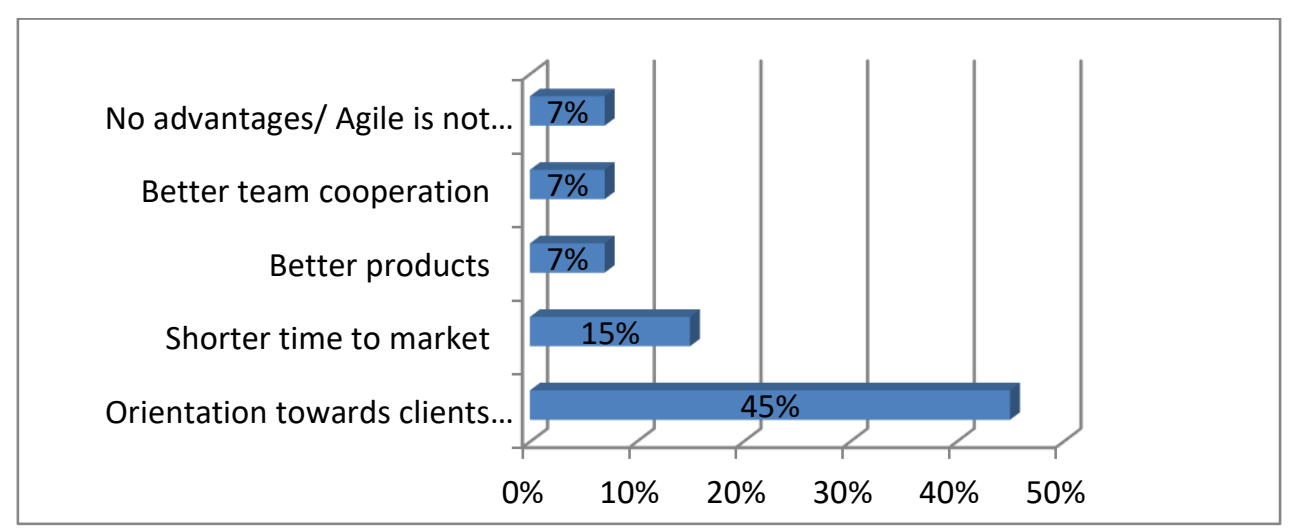

Figure 4. Perceived social and financial advantages of using Agile in software development according to experts' statements

Source: author's own research

Another aspect taken into consideration are the specific elements, that are brought to the daily activities by the Agile method, such as: weekly meetings with team members to discuss results and improvement solutions (70\%); the necessity of a monthly product release, that stimulates the overall team (54\%); cooperation with members of other departments to discuss results and bring potential improvements (39\%); direct meetings between managers and clients to bring clients' feedback $(15 \%)$ (See Figure 5). Most experts mentioned the ability of the Agile method to stimulate a dynamic pace of work, that allows frequent improvements of the products and usually a monthly release and the necessity of frequent meetings with the manager and the team to discuss results and further improvements. 39\% of the participating experts also had to cooperate with member of other departments to discuss results.

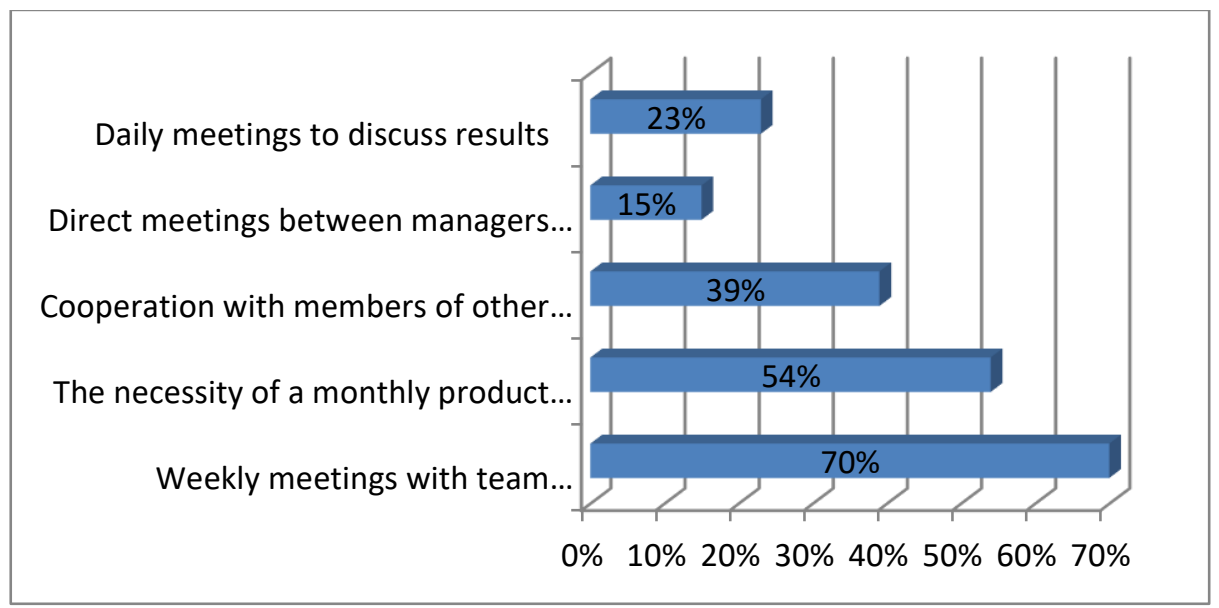

Figure 5. Specific elements of the Agile method implemented in the daily activity of the experts' departments

Source: Author's own research 
Regarding the motivation of the employees brought by the implementation of the Agile model, that were mentioned by the participating experts, an interesting fact was that the self-fulfilment benefits, such as the chance to express and implement one's own ideas suggested to managers and/or clients (46\%) or the possibility of learning from members of other departments (46\%) were the main advantages perceived. On the opposite side only $8 \%$ of the experts mentioned the financial rewards in the form of bonuses for extra hours as an advantage. The other members mentioned such extra hours were not offered by their companies.

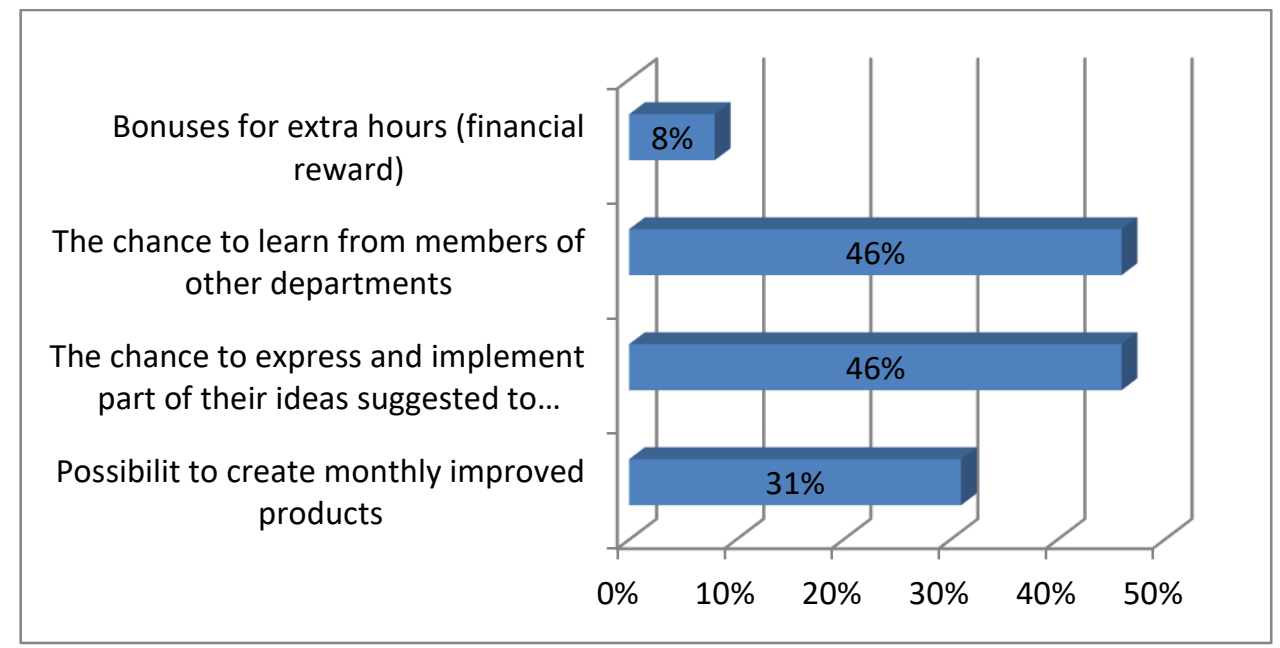

Figure 6. Specific elements of the Agile method implemented in the daily activity of the experts' departments

Source: Author's own research

Another debated aspect was represented by the weaknesses of the Agile model implemented in the management of software development in one's own company. The main issues, that were perceived by the employees participating in the study were: weak time estimations and planning (39\%), personnel problems, such as conflicts, stress, mismanagement in teamwork, etc. (15\%), quality of products, that can suffer (7\%). The majority of the experts mentioned lacking planning and time estimations, that can bring organizational and programming issues, such as delayed releases, errors in the programming, mismatch in team management and other such aspects. Furthermore, $47 \%$ of the experts mentioned their companies will not switch to another type of model and $23 \%$ did not offer a response. Only one expert mentioned their company intends to choose a safe type of model for the future. The rest of the experts did not know or mentioned it would be a disadvantage to switch from such a model. 


\section{Conclusion}

In this paper we aimed to research the specific characteristics of the Agile model as applied to the companies in the IT field, that were selected for the study. The second hypothesis of the study was also confirmed that the Agile method has as one main advantage a better orientation towards clients and involves them directly in the software development, thus, increasing the chance for better improvements of the products. Moreover, most experts found that their company does not intend to move to another type of model and perceive the Agile as bringing benefits to the company and the team.

In the IT field there are new challenges to be expected in the future as requirements from different parties and fields are increasing and therefore, more innovation and adaptation to a faster pace of customer needs is necessary. This implies the need for frequent cooperation between departments, managers, employees for the companies in this field, in order to adapt and joint the efforts towards building a new direction in the sense of customer focus and expansion of the activity.

In this way, the software development process is no longer viewed in a static way from requirements analysis to design, implementation and only afterwards customer feedback, but allows and encourages customer involvement in the process.

The IT field is expected to continue its evolution in the direction of digitalization of more aspects of the daily activity, that will bring changed customer requirements and preferences, contributing as well to the evolution of the software development models depending on the market changes. While the Agile model is considered to offer currently the most adaptive type of behaviour of IT companies to customer needs and requirements, additions and changes of the model can be expected in the future in order to focus even more on clients' needs.

A future research objective of the present study would be to observe this evolution of the Agile model and its implementation in several IT companies, as the models for software production are evolving individually as well, the trend being that of stakeholders' involvement in the process in order to increase accuracy of the feedback integrated in the improved versions of the products. The relevance of this subject lies in the fact that as organizational cultures and management strategies could change thoroughly and affect employees' behaviour and company perspective towards customers and other stakeholders.

\section{References}

Ambler, S.W. (2004). The object primer: Agile Model -Driven Development with UML 2.0, Cambridge University Press, New York.

Buch (2012). Shared Knowledge. Köln, Josef Eul Verlag.

Canty, D.(2015). Agile for Project Managers. Florida, CRC Press.

242 Review of International Comparative Management

Volume 19, Issue 3, July 2018 
Chandrasekara, C. (2017). Beginning Build and Release Management with TFS 2017 and VSTS: Leveraging Continuous Delivery for Your Business. Sri Lanka, APRESS.

Comptia (2018). IT industry outlook. https://www.comptia.org/resources/itindustry-trends-analysis.

Paranj, B. (2017). Test Driven Development in Ruby: A Practical Introduction to TDD Using Problem and Solution Domain Analysis. Georgia, APRESS.

Paranj, B. (2017). Test Driven Development in Ruby: A Practical Introduction to TDD Using Problem and Solution Domain Analysis. Georgia, APRESS.

Puri, C.P. (2009). Agile Management: Feature Driven Development. New Delhi, Global India Publications Pvt Ltd.

Pycek, R. (2009). Suitability of Modern Software Development Methodologies for Model Driven Development. JIS, 33, pp. 285-295.

Pope-Ruark, R. (2015). Introducing Agile Project Management Strategies in Technical and Professional Communication Courses. Journal of Business and Technical Communication, 29(1), pp. 112-133.

Sharma, S., Sarkar, D., Gupta, D. (2012). Agile Processes and Methodologies: A Conceptual Study. International Journal on Computer Science and Engineering, 4(5), pp. 892-898. 